\title{
Recycling Practice to Promote Sustainable Behavior at University Campus
}

\author{
Shahrom Md Zain ${ }^{1}$, Noor Ezlin Ahmad Basri ${ }^{1}$, Nur Ajlaa Mahmood ${ }^{1}$, Hassan Basri ${ }^{1}$, Norhidayu Zakaria ${ }^{1}$, \\ Rahmah Elfithri ${ }^{2}$, Maisarah Ahmad ${ }^{3}$, Tiew Kian Ghee ${ }^{1} \&$ Zarina Shahudin $^{1}$ \\ ${ }^{1}$ Department of Civil \& Structural Engineering, Faculty of Engineering \& Built Environment, Universiti \\ Kebangsaan Malaysia, Selangor, Malaysia \\ ${ }^{2}$ Institute for Environment \& Development (LESTARI), Universiti Kebangsaan Malaysia, Selangor, Malaysia \\ ${ }^{3}$ Business Management Studies Centre, Faculty of Economics \& Business,Universiti Kebangsaan Malaysia, \\ Selangor, Malaysia
}

Correspondence: Shahrom Md Zain, Department of Civil \& Structural Engineering, Faculty of Engineering \& Built Environment, Universiti Kebangsaan Malaysia, 43600 UKM Bangi, Selangor, Malaysia. Tel: 60-3-8921-8338. E-mail: smz@eng.ukm.my

\author{
Received: October 5, 2012 Accepted: November 7, 2012 Online Published: November 30, 2012 \\ doi:10.5539/ass.v8n16p163 URL: http://dx.doi.org/10.5539/ass.v8n16p163
}

\begin{abstract}
In this paper, attitudes toward sustainable behavior refer to an individual's responsibility in using the natural resources granted by Allah S.W.T. while taking into consideration the interests of future generations. These actions must start from oneself, and include simple and immediately necessary actions. For example, recycling is a simple practice that must be engaged in by all individuals. As a leading university that launched a SUSTAINABLE PROGRAM involving the majority of its highly educated community, its image would be tarnished if this simple practice was not carried out. Universiti Kebangsaan Malaysia (UKM), through its zero waste campus initiative and in collaboration with the research group of Alam Flora Sdn Bhd, has deployed recycling activities effectively since 2010 using an improved a management recycling system, improving existing facilities and intensifying awareness campaigns. However, the response from the UKM community is low, with an average recycling rate of $1.75 \%$ (April 2010 to July 2012) and an average of eight persons/week who sent recyclable items to the UKM Recycling Center (April 2011 to July 2012). Surveys taken regarding the involvement of the UKM community in recycling activity are discussed to obtain an overview of the facilities and the changes required to improve the recycling management system. Based on a problem analysis using a fishbone diagram, peoples' attitudes are shown to be a primary cause of the low response to the recycling program. The targeted recycling rate of $20 \%$ requires the continued cooperation and efforts of the entire UKM community to promote an educated culture of sustainability at the University.
\end{abstract}

Keywords: recycling, sustainable behavior, attitude, Universiti Kebangsaan Malaysia (UKM), survey

\section{Introduction}

Attitude is defined as a person's reaction through the soul, whose behavior can become a common habit. Attitude determines whether a person's actions are positive or negative. Sustainable attitudes and behaviors in this paper are considered positive dispositions toward practicing, in daily life, actions that demonstrate care for the environment and the needs of present and future generations. One example is recycling. Why do we need to recycle? What are the consequences if we do not recycle? The answers to these questions have been featured in many print and electronic media to create awareness in the hope that these practices will gain universal support. However, these efforts, to some degree, have failed to educate and create awareness, and some look down on these efforts, thinking that the issue of recycling is unimportant and there are more pressing issues that need to be addressed.

Recycling can be defined as the recovery of waste from products through their reuse, either for their original purpose or for other purposes. There are many different views and studies related to recycling behaviors that aim to understand what people require to participate in recycling. Alfroz, Hanaki, Tuddin and Ayup (2010), in their study regarding factors that influence the attitudes and behaviors towards recycling among 465 households in 
Dhaka, Bangladesh, found that environmental awareness, storage space and age (25-35 years) are the factors that influence engaging in recycling behavior. Timlett and Williams (2011), in a study based on a literature review and survey analysis of participation in recycling activities by the community of the City of Portsmouth, England, have identified three main factors that contribute to effective recycling programs: infrastructure, services and behaviors (ISB). From this research, they produced an ISB model that can be used by waste management practitioners to better understand the conditions and behaviors needed to maximize recycling.

The research of 'comparison of waste prevention behaviors among three Japanese megacity regions in the context of local measures and socio-demographics' by Kurisu and Bortoleto (2011) proved that local policies and measures become the factors of human behavior towards recycling. It is showed that Osaka has larger waste generation per capita and lower recycled ratio that Tokyo and Aichi. The waste management of household wastes in Osaka ie relatively advanced than that in Tokyo and Aichi. Another factor influencing people's behavior toward recycling is their income. From Yung (2011) research show that socio-demographic factors such as education level, gender and household size do not hold any relevancy in determining waste recycling behavior. But he found out that household income is the only socio-demographic factor with significant relationships with the amount of recyclables collected. This factor is also agreed by Qingbin, Zhishi and Jinhui (2012) where the respondent does not want to pay for their recycling e-waste because some of them have a lower income or who considered the economy to be depressed, thought that payment for e-waste disposal would increase their cost of living in the future. Research done by Prestin and Pearce (2010) proved that the knowledge and information given to the users are the same for all education level. This is where they give adolescents tools to their participants, which are school children to communicate about recycling that can help to expand beyond the schools. Not only that, they found out that participants believed recycling was a good behavior with positive results.

The Organisation for Economic Co-Operation and Development [OECD] (2008) reported on a study conducted in Rice County (Minnesota) regarding recycling. The study, which involved 1000 households, found that infrastructure factors, including increased the frequency of recycling collection (from two weeks to every week), less need for separation (transition from several separate bins to one large bin for recyclable materials) and a more convenient location for the collection of recyclable items. Convenient location can be supported by Zhang, Williams, Kemp and Smith (2011) research which stated that convenience is incorporates into two features: the distance to the collection spot where recyclables are carried to and the time spent on recycling activities. It is important to provide an easy access infrastructure for the users. However, efforts using education to raise awareness about recycling have less impact on people's recycling behavior. Other researchers conducted a study on the relationship between religion and environmental behavior to understand to what extent religion can make one concerned about environmental preservation. Mashitoh (2007) reported on a survey related to religious factors influencing behavior in relation to the environment. She found that there were differences of opinion among authors, with some stating that religion does not have a significant influence on environmental behavior and another stating that religion has a positive relationship with environmental awareness.

This paper discusses efforts made to provide the best recycling management system for UKM by focusing on the attitudinal and behavioral problems that cause low participation in recycling programs. Surveys on recycling activities were administered to the UKM community to obtain an overview of the requirements and facilities needed. The views and comments of the respondents are essential to improve recycling management systems and to cultivate and develop pro-recycling attitudes and behaviors among the UKM community.

\section{Recycling Management in UKM}

UKM, through the research group on the zero waste campus initiative, in collaboration with Alam Flora Sdn Bhd, has deployed recycling activities more effectively since 2010 to improve recycling management systems, improve existing facilities and centers, and intensify awareness campaigns. In the initial stages, in April 2010, the Mobile Recycling Center (truck) (Figure 1) operated on the Tuesday of the first week of every month. There are two types of collection: one for recycled paper from every office and one for recyclable items from the entire UKM campus, collected by placing a recycling truck at the Dataran Panggung Seni UKM between 12 noon and $2 \mathrm{pm}$. There were 62 coordinators appointed, one for each paper recycling box location, and they are responsible for collecting the recyclable paper in their offices. 


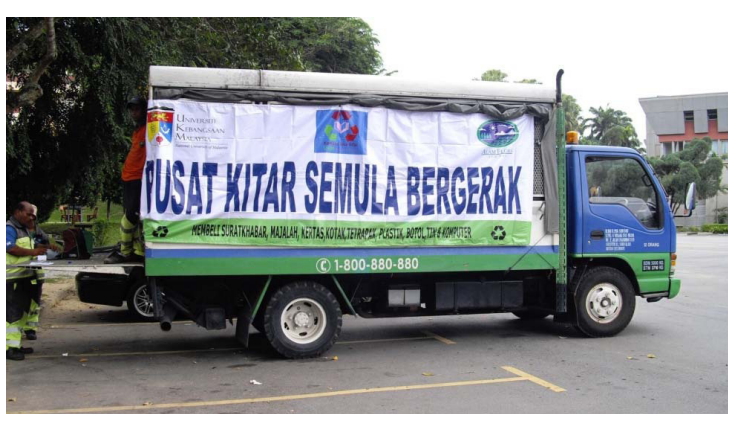

Figure 1. Mobile recycling centre

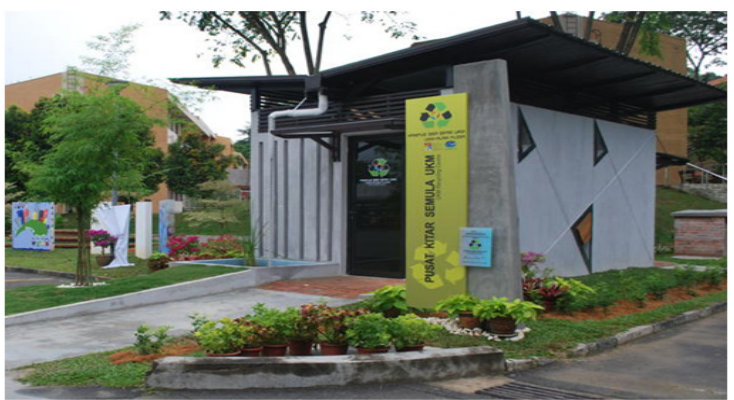

Figure 2. Recycling center at Dataran Panggung Seni

To provide a better facility for all users, the Recycling Center (PKS) was constructed and began operation on 5 April 2011 (Figure 2). The PKS is located at Dataran Panggung Seni UKM. Purchase operations (buy-back) for the recyclable items are carried out by Alam Flora Sdn Bhd every Tuesday from 12 noon to 2 pm. However, drop-off operations (Figure 3) are available any time by placing recyclable items into the containers provided (paper, plastic, glass, cans / metals and tetrapak). Several issues, including the use of recycling bank books, pricing, the sale of recyclable items and the scheduling of recycling operations need to be taken into account to understand the overall operation of the recycling center and the periodic improvements that were needed.

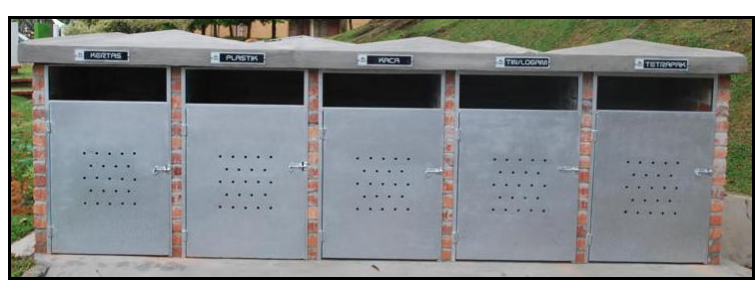

Figure 3. Drop-off boxes

Two waste separation systems were introduced in UKM: paper-recycling boxes (Fig. 4a), which were placed in the offices, and a two-bin system (Figure 4b) placed in strategic locations in University buildings. These two systems are among the options provided to facilitate the separation of waste.

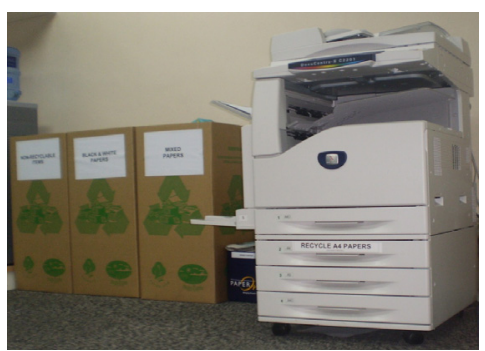

(a)

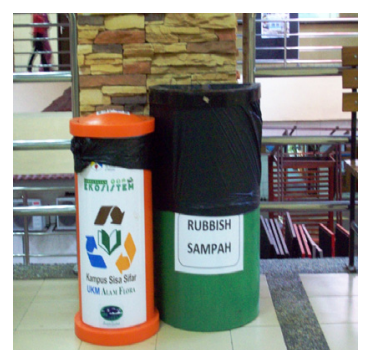

(b)

Figure 4. (a) Paper recycling box and (b) Two-bin system

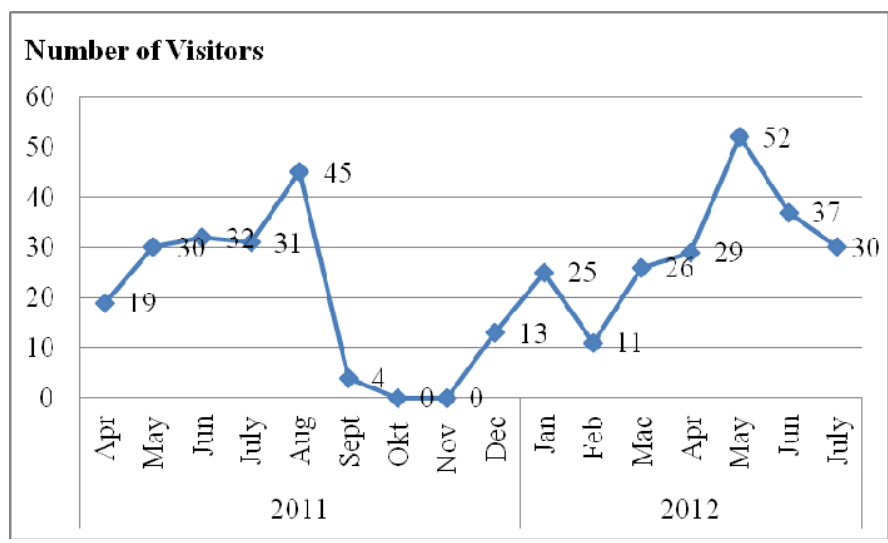

Figure 5. Number of visitors to the Recycling Center (Apr 2011- July 2012) 
Figure 5 show the number of visitor deposited recyclables and offices that are using the PKS service from April 2011 to July 2012 where the average number of visitor is 8persons/week. Even thought the average show a low number of visitors but the numbers have increased starting January 2012. The increment may due to the changes of operation day from once a week to three times a week, from Monday to Wednesday. In 2011, PKS only operated on Tuesday from 12 to $2 \mathrm{pm}$ but with the new operation day the time is also changes from 9.30am to $5.30 \mathrm{pm}$. The average of regular visitor is once in two months that is proven by the fluctuation from January to July 2012. Several strategies have been done to increase the number of visitor such as promoting PKS via emails, buntings and digital board. Education is also given to the visitor by teaching them about the right way of recycling including proper storage and sorting.

Figure 6 show the fluctuation of recyclables percentage in PKS UKM. There are huge increment in December 2010 and May 2012, this may cause by end of semester at that particular year. While decrease at the end of 2011 may due to the changes of management from Alam Flora Sdn Bhd to students management. If we make a comparison with Figure 5, visitors tend to bring small amount of recyclables.

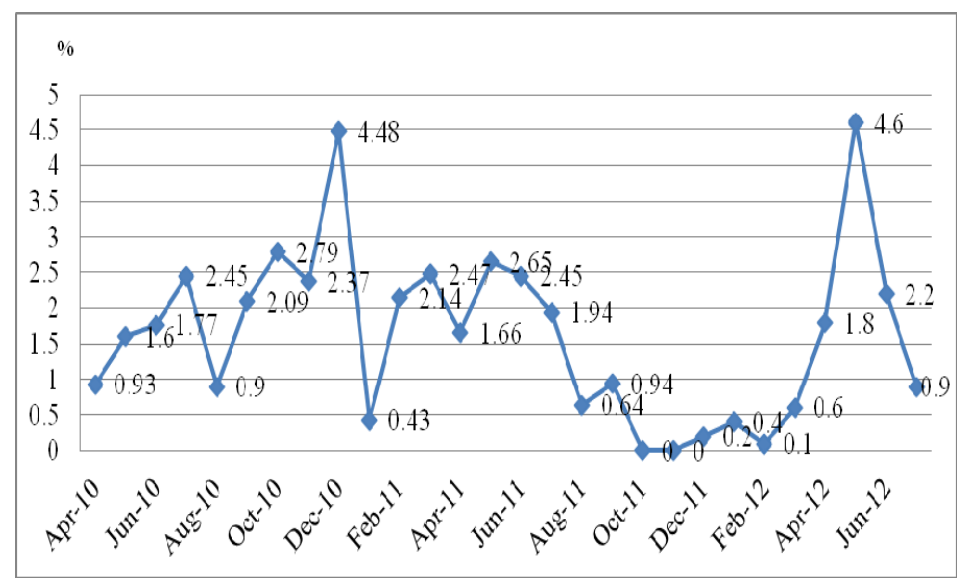

Figure 6. Percentage of recycling in UKM (April 2010 to July 2012)

\section{Questionnaire on the Facilities and Activities of Recycling in UKM}

In the early stages, the questionnaire-based survey was conducted to determine how many UKM students and staff were aware of the existing of facilities and University's recycling programs. A total of 100 respondents responded to the questionnaire. Among those who responded, $96 \%$ were students and $4 \%$ were staff.

\subsection{Mobile Recycling Center}

Based on the survey (Figure 7), it was found that $29 \%$ of the respondents were aware of the Mobile Recycling Center program, while $54 \%$ were unaware of it and $17 \%$ were unsure. More than $50 \%$ of the respondents did not know about the program because of the lack of publicity and because the location of the campaign was unsuitable. Each month, two or three days before the recycling operation, information about the recycling operations is shown on the large TV screen near the main entrance to the University. Apart from this screen, the information is distributed through e-Warga, which is the e-mail system serving all students and the Faculty / Department / Institute / Center. This result shows that advertising through these media has far less impact.

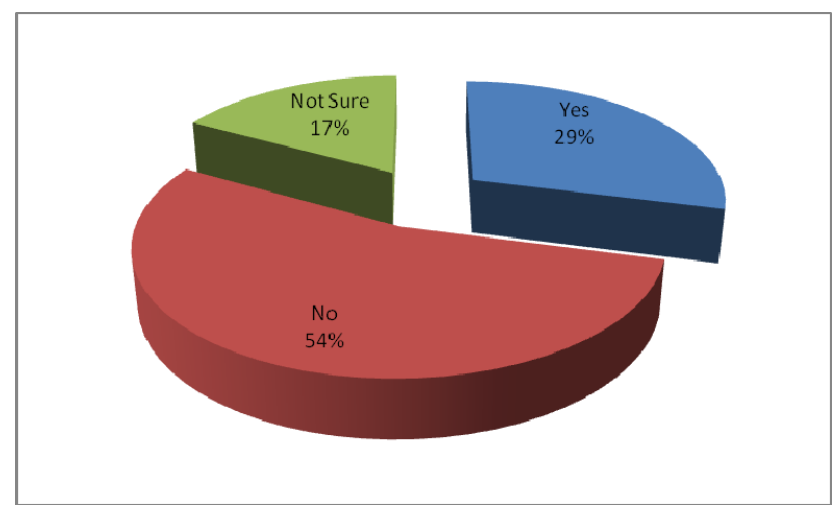

Figure 7. Do you know about the operation of the Mobile Recycling Center UKM? 


\subsection{Two-bin System}

The results of the survey (Figure 8 ) show that $88 \%$ of the respondents knew about the orange bins, while $8 \%$ did not know and $4 \%$ were not sure. These results indicate that there were respondents who did not know about the two-bin system implemented at the University. The respondents felt that they lacked clarity about the use of the orange bins placed in the faculty buildings. Some of the respondents felt that the bins should be placed in the residential college buildings, as many recycled waste materials are produced large quantities in the residential colleges.

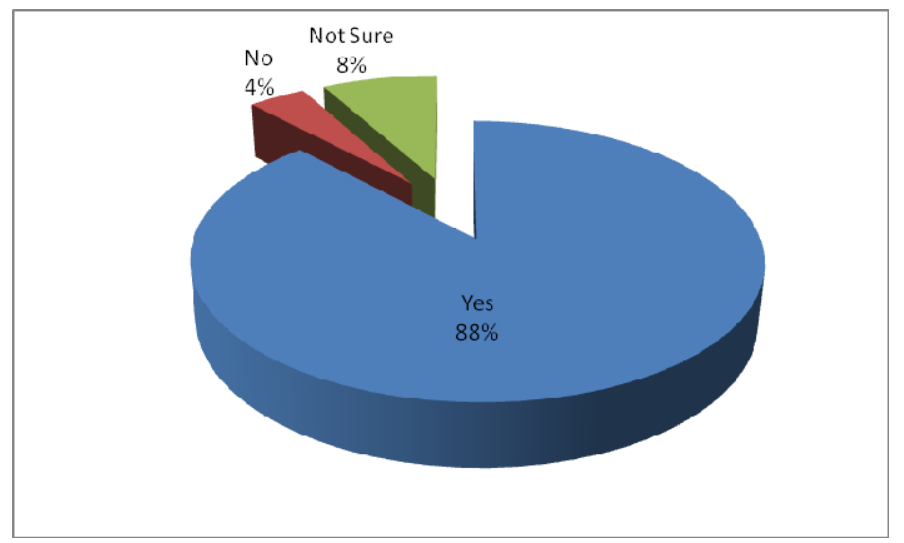

Figure 8. Were you aware of the existence of an orange bin (two-bin system) at the University?

The two-bin system has been expanded to strategic locations in existing buildings around UKM using glued labels on the opened / closed doors and attaching them to the relevant posters. Based on Figure 9, it was found that $85 \%$ of the respondents used the orange bins, $10 \%$ did not use them and the remaining $5 \%$ were unsure. Although the largest percentage was of those who used the orange bins, they still felt that the information about how to use of the bins was lacking, and they were unsure whether they deposited the correct materials in a bin. Some of the respondents said they were uncertain because they had thrown trash in the bins nearest them, thinking all of the bins available were ordinary bins. Many of the respondents hoped that publicity about the use of bins would be increased, and many acknowledged the benefits of an education program for the UKM community that would help people recognize what waste can be recycled and how they can separate recyclable materials from disposable waste.

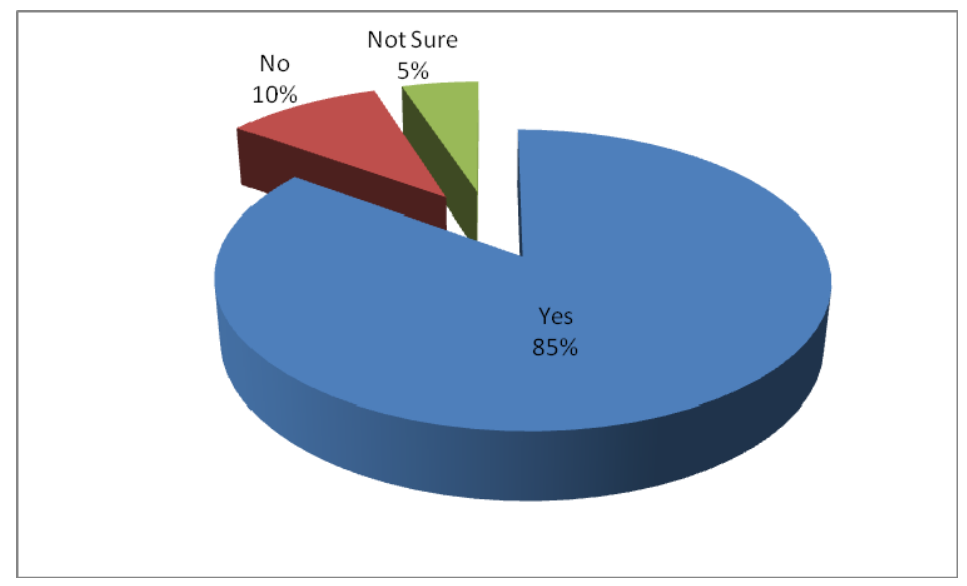

Figure 9. Usage of orange bin (two-bin system)

\subsection{Paper Recycling Boxes}

Figure 10 shows that $76 \%$ of the respondents knew about the paper recycling boxes that are located in almost all the offices at UKM, while $13 \%$ were unaware and the remaining $11 \%$ were unsure. There were respondents who did not know about this program even though it has been in place since April last year; this is because the respondents did not work in an office; some of them stated that a recycling box was not supplied, and others stated that they were busy with learning activities, so they did not participate in the program. 


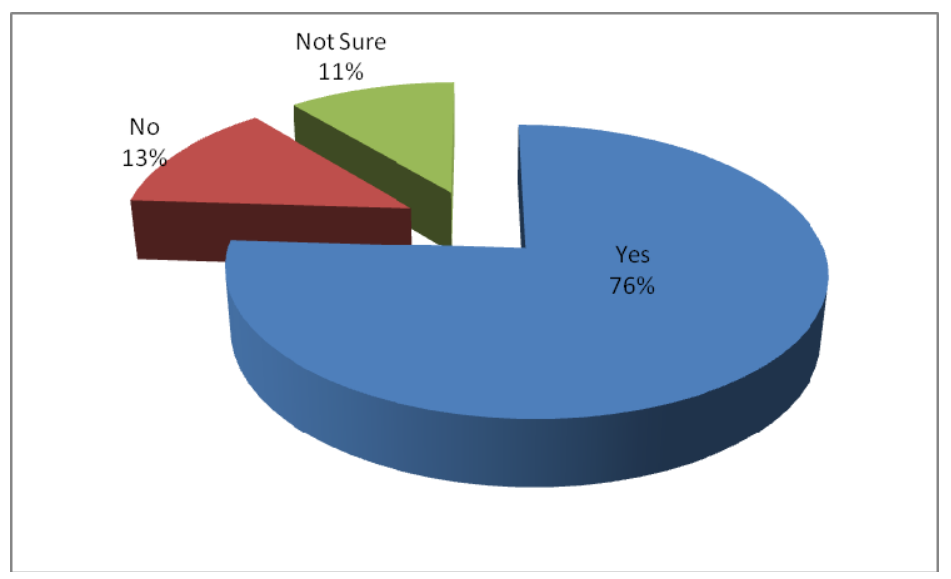

Figure 10. Did you know about the paper recycling boxes placed in offices?

\subsection{Knowledge about Recycling}

Figure 11 shows the percentage of respondents who are aware of which materials can be recycled. Of the total respondents, $98 \%$ knew which materials can be recycled, $1 \%$ did not know and $1 \%$ were not sure. This result shows that the majority of respondents know which materials can be recycled but that $2 \%$ do not know. A lack of interest is one of the reasons why respondents did not know about the material can that be recycled.

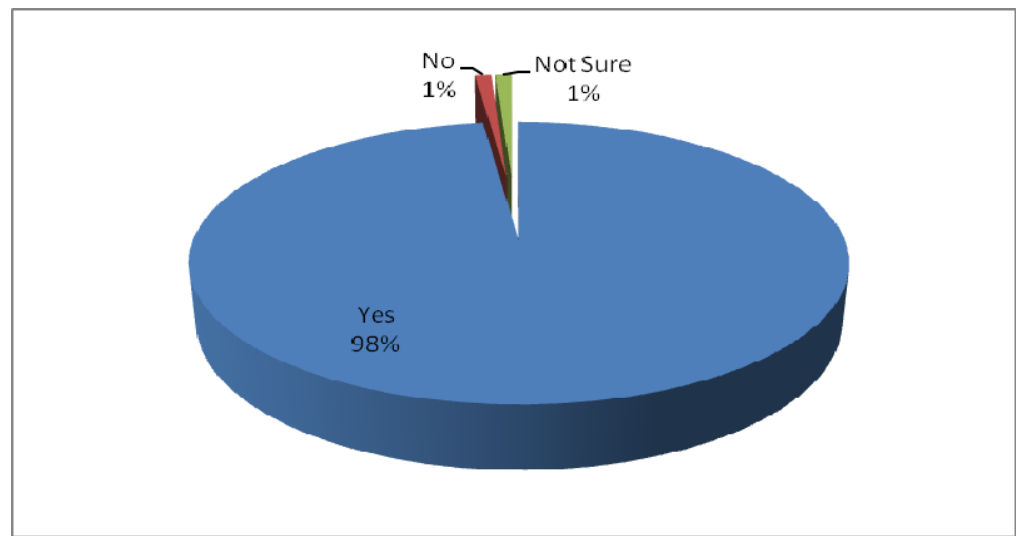

Figure 11. Knowledge about recycling among the UKM community

\subsection{Suitability of the Operating Hours of the Recycling Center UKM}

Regarding the suitability of the operating hours of the Recycling Center (Figure 12), the survey found that $61 \%$ of respondents felt that the operating hours were suitable, while $20 \%$ thought otherwise and $19 \%$ were unsure. The $20 \%$ of the respondents who answered that the hours were unsuitable stated that the operation was during lunchtime and that hot weather made it difficult for them to bring items to the Recycling Center. Moreover, many of the respondents had a full schedule on Tuesday, which deterred them from delivering their recyclables. However, the respondents also suggested additional suitable operating hours for the Recycling Center, such as every day during office hours, three times a week at the same time and weekends from 8 am to 12 noon or 12 noon to $4 \mathrm{pm}$. Due to constraints in terms of labor, the PKS cannot be operated as intended. 


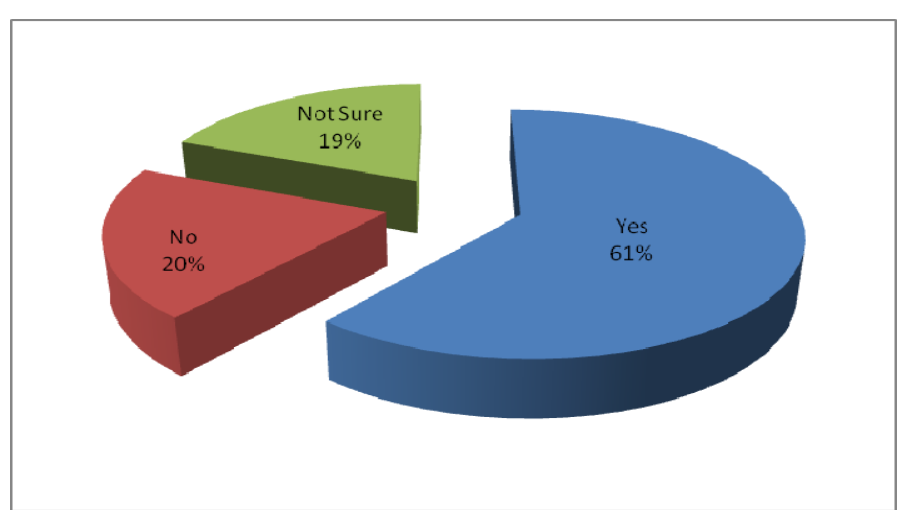

Figure 12. Suitability of the operating hours of the recycling center UKM

\subsection{PKS as the Best Recycling Facilities}

Figure 13 shows that $85 \%$ of the respondents agreed that the Recycling Center is the best facility to carry out recycling activities on the University campus, while $4 \%$ did not agree and $11 \%$ did not know. There were a number of respondents who did not agree because they felt the location of the Recycling Center was not optimal and that they were too far from the facility. Some students reported difficulty carrying recyclable materials such as paper because it was too heavy. The distance between bus stops and the recycling centers was a hindrance to students who did not have private vehicles.

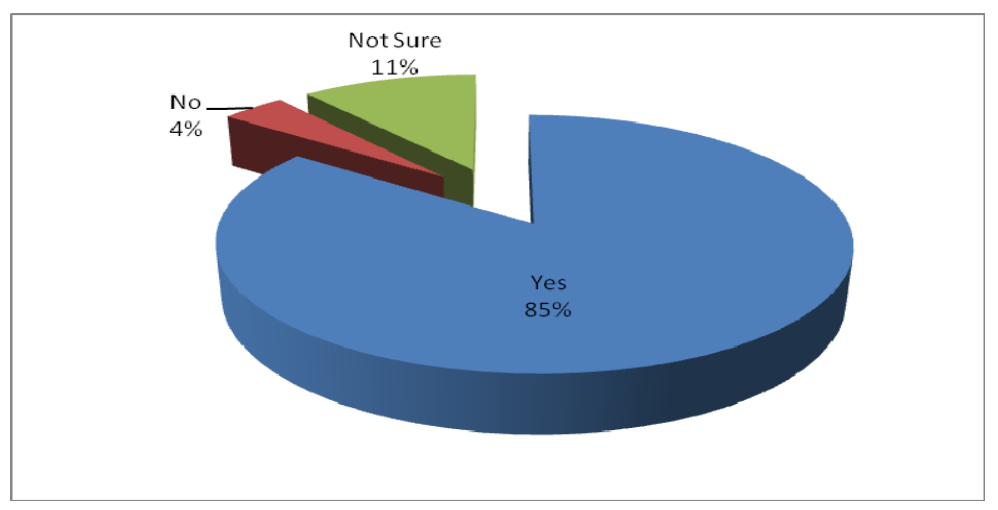

Figure 13. PKS as the best recycling facilities

\subsection{Willingness to Participate in Recycling Activities}

Only $77 \%$ of the respondents were willing to participate in recycling activities, as shown in Figure 14. Of the remaining respondents, $11 \%$ were not willing and $12 \%$ were unsure. The respondents who were willing to participate thought that the practice of recycling is important for preserving the environment and that it can indirectly cultivate self-awareness. Respondents who were not prepared to get involved said that they would be graduating this semester and that it was unnecessary to be involved. Some would argue that they should not be involved if they did not take the course. Other respondents who were working stated that they did not have enough time to get involved. Most respondents agreed that all of the implemented programs should be continued. They felt that all activities carried out through the program can contribute to a healthy environment through the adoption of a sustainable lifestyle. However, some respondents felt that the facilities provided for recycling were insufficient to make recycling easy for the UKM community, mainly because the location of the Recycling Center is distant from the bus stop, inconveniencing those who do not have a vehicle to deliver the recyclable materials. 


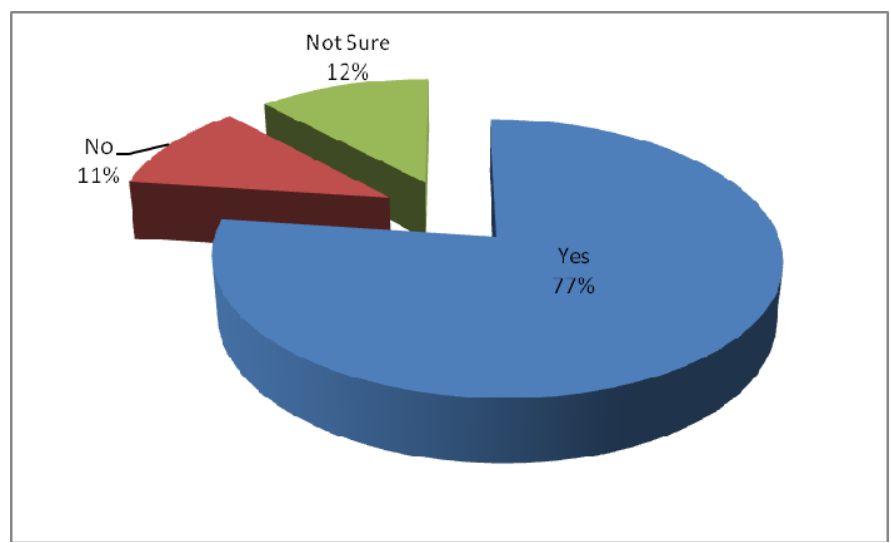

Figure 14. Willingness to participate in recycling activities

\subsection{The Necessity for Publicity and a Campaign}

The survey results show that some groups were aware of the recycling activities undertaken at UKM, while only a small group was unaware. This lack of awareness was due to a lack of publicity for the recycling activities. Therefore, a pilot program conducted by students was taken up, putting posters throughout the UKM area, such as in the facilities, residential colleges, faculty buildings, offices and bus stations to make UKM students and staff aware of and able to take part in the activities. The pilot programs were divided into several groups, and each group was given a specific location. A total of 250 posters have been successfully placed around the UKM campus. Awareness campaigns on recycling activities are also arranged occasionally to provide reminders and information to the UKM community. Table 1 shows the activities carried out from March 2010 to April 2012 to inform the community about the recycling activities at UKM.

Table 1. Activities related to recycling in UKM

\begin{tabular}{ll}
\hline Activities by Initiatives of the Zero Waste Campus Group Date &
\end{tabular}

3R for better environment exhibition 10-12 March 2010

Tapau-Mania (Organized by Ibu Zain College)

8 July 2010

No polystyrene campaign

Launching of O-Waste Campus (Organized by Student Club PPPM)

12 October 2010

Awareness talk on 3R

Collection of recycleables materials

Exhibition of posters

Talk on Zero Waste Campus to first year students in conjunction with an orientation 16 October 2010 session

Towards a Zero Waste Campus (Organized by Jaksa Rahim Kajai College)

27 Dec 2010 to 3

No polystyrene

March 2011

Environmental talk

Nature aerobic

Waste management workshop

Recycling competition

Manual T-Shirt printing

Collection of recyclable materials

Environmental Carnival at Ibu Zain College (Organized by Executive Student Council 14 - 16 January 2011 IZISH)

Campaign of $3 \mathrm{R}$

Earth Voice

Green Run 
Recycling Management Workshop (Organized by Initiatives of Zero Waste Campus 3 March 2011 research group and Alam Flora Sdn Bhd)

Snap \& Win Contest (Zero Polystyrene)

9 \& 10 March 2011

Launching of Recycling Center UKM

23 March 2011

Environmental poster exhibition

Give certificates of appreciation to the best coordinators and highest papers collection

Sustainable activity in Entrepreneurship Week and Sustainable Campus (new student orientation for session 2011/2012):

Develop a Mini Recycling Center

Polystyrene and Zero Plastic Bag Campaign

Water and Energy Saving Campaign

Green College

Zero Smoke Campaign

Action on Lestari@Facebook

Programme with Alam Flora (new student orientation for session 2011/2012)

New management team for PKSUKM

Recyclables Purchasing Operation

12-18 September 2011

Office Paper Collection

Marketing Activities to Promote PKSUKM

Sustainable Campus Carnival

12 May 2012

Intercollege Recycling Collection Competition

Run to be Green

Sustainable Mural Painting Competition

Opening Ceremony of EcoVolunteer UKM

Care for Nature Seminar (Organized by Zero Waste Group)

14 September 2011

December 2011-

present

\section{Analysis of Technical Problems Using a FishBone Diagram}

The fishbone diagram is a simple method to summarize, organize and explain in diagram form all the causes of an identified problem. In this case, the problem is titled "do not practice recycling." The author used this technique to identify the cause of non-participation in recycling programs. The steps taken in developing this diagram are as follows: identify the problem by writing it on the right, draw the main branches of the fishbone, where the branches are the cause or source of the problem identified (human, environment, methods, facilities, equipment and materials) and then determine the less significant reasons under the main reasons (Figure 15). The diagram can be created using Microsoft Excel. If a problem is repeated in the branches, it shows that it is a major cause. The results from the preliminary analysis show that attitude and behavior are the main causes of individuals not practicing recycling. 


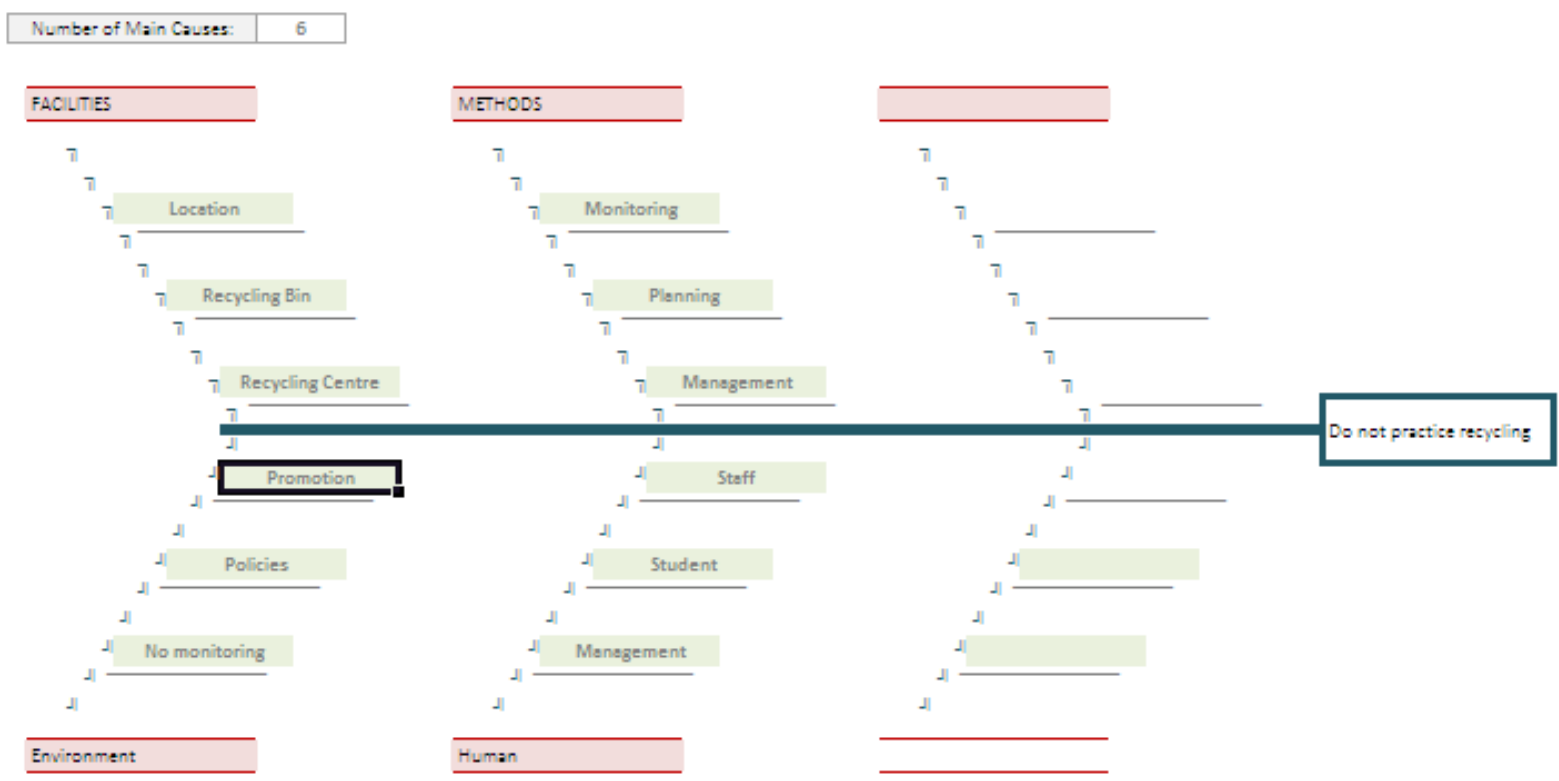

Figure 15. Sample of problem analysis "do not practice recycling" fishbone diagram method

\section{Conclusion}

Where is the flaw in a recycling management system if it is unable to achieve high collection targets? Are management systems that do not provide the best facilities the cause? Is it an awareness campaign that is not carried out effectively? Or do individual attitudes play a major role? A questionnaire-based survey was carried out to improve the shortcomings that arose in providing the best facilities and services for recycling, including establishing the UKM Recycling Center. Constraints caused by the operation of the PKS UKM and transport facilities will be considered when examining how to improve the existing management system to further encourage the UKM community to participate in recycling activities and thus how to influence their behavior toward a more sustainable attitude. A change of attitude among the UKM community, though, is more important and is expected. If the individual has knowledge and is aware of the importance of recycling, but takes no action, the initiative will not succeed. The movement of individuals toward positive attitudes and behaviors regarding sustainable practices can affect the success of recycling activities at UKM.

\section{Acknowledgements}

The author would like to express appreciation to UKM for grant UKM-PTS-096-2010 and PTS-2012-096 to conduct research on the effectiveness of recycling activities at UKM by establishing the UKM Recycling Center and improving the recycling management system. The author gratefully acknowledge to UKM for grant OUP-2012-126. Appreciation also goes to Alam Flora Sdn Bhd, who has given valued cooperation in the UKM Zero Waste campus research projects, in addition to all the members of the Zero Waste Campus who together contributed their knowledge and energy. This work supported by the Centre for Engineering Education Research, Faculty of Engineering and Built Environment, Universiti Kebangsaan Malaysia, Bangi, Selangor, Malaysia. May Allah bless these efforts.

\section{References}

Afroz, R., Hanaki, K., Tuddin, R., \& Ayup, K. (2010). A survey of recycling behaviour in households in Dhaka, $\begin{array}{llll}\text { Bangladesh. Waste } \quad \text { Management } & \text { 28 }\end{array}$ http://dx.doi.org/10.1177/0734242X09353434

Kurisu, K. H., \& Bortoleto, A. P. (2011). Comparison of waste prevention behaviors among three Japanese megacity regions in the context of local measures and socio-demographics. Waste Management, 31, 1441-1449. http://dx.doi.org/10.1016/j.wasman.2011.03.008

Organisation for Economic Co-Operation and Development (OECD). (2008). Household behaviour and the 
environment: Reviewing the evidence. OECD Publication.

Prestin, A., \& Pearce, K. E. (2010). We care a lot: Formative research for social marketing campaign to promote school-based recycling. Resources, Conservation \& Recycling, 54, 1017-1026. http://dx.doi.org/10.1016/j.resconrec.2010.02.009

Qingbin, S., Zhishi, W., \& Jinhui, L. (2012). Residents' behaviors, attitudes, and willingness to pay for recycling e-waste in Macau. Journal of Environmental Management, 106, 8-16. http://dx.doi.org/10.1016/j.jenvman.2012.03.036

Timlett, R., \& Williams, I. D. (2011). The ISB model (infrastructure, service, behaviour): A tool for waste practitioners. Waste Management, 31(6), 1381-1392. http://dx.doi.org/10.1016/j.wasman.2010.12.010

Yaacob, M. (2007). Religious factors and environmental behaviour: A review of the profesional literature. Jurnal Pengajian Umum, 7, 27-40.

Yung, Y. (2010). Domestic waste recycling, collective action and economic incentive: The case in Hong Kong. Waste Management, 30, 2440-2447. http://dx.doi.org/10.1016/j.wasman.2010.06.009

Zhang, N., Williams, I. D., Kemp, S., \& Smith, N. F. (2011). Greening academia: Developing sustainable waste management at Higher Education Institutions. Waste Management, 31, 1606-1616. http://dx.doi.org/10.1016/j.wasman.2011.03.006 